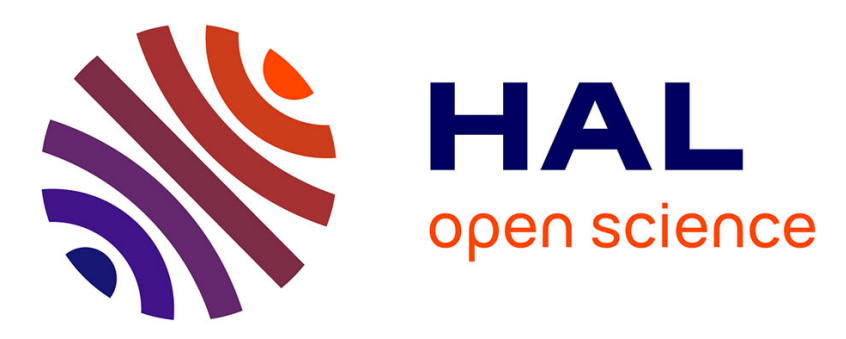

\title{
Anticipating aging failure using feedback data and expert judgment
}

François Pérès, Leïla Bouzaïene, Jean-Claude Bocquet, François Billy, André Lannoy, Philippe Haïk

\section{- To cite this version:}

François Pérès, Leïla Bouzaïene, Jean-Claude Bocquet, François Billy, André Lannoy, et al.. Anticipating aging failure using feedback data and expert judgment. Reliability Engineering and System Safety, 2007, vol. 92 ( $\mathrm{n}^{\circ}$ 2), pp. 200-210. 10.1016/j.ress.2005.11.063 . hal-01295842

\section{HAL Id: hal-01295842 \\ https://hal.science/hal-01295842}

Submitted on 31 Mar 2016

HAL is a multi-disciplinary open access archive for the deposit and dissemination of scientific research documents, whether they are published or not. The documents may come from teaching and research institutions in France or abroad, or from public or private research centers.
L'archive ouverte pluridisciplinaire HAL, est destinée au dépôt et à la diffusion de documents scientifiques de niveau recherche, publiés ou non, émanant des établissements d'enseignement et de recherche français ou étrangers, des laboratoires publics ou privés. 


\section{Open Archive TOULOUSE Archive Ouverte (OATAO)}

OATAO is an open access repository that collects the work of Toulouse researchers and makes it freely available over the web where possible.

This is an author-deposited version published in : http://oatao.univ-toulouse.fr/ Eprints ID : 10336

To link to this article : DOI : 10.1016/j.ress.2005.11.063

URL : http://dx.doi.org/10.1016/j.ress.2005.11.063

To cite this version : Pérès, François and Bouzaïene, Leïla and Bocquet, Jean-Claude and Billy, François and Lannoy, André and Haïk, Philippe Anticipating aging failure using feedback data and expert judgment. (2007) Reliability Engineering and System Safety, vol.92 (n²). pp.200210. ISSN 0951-8320

Any correspondance concerning this service should be sent to the repository administrator: staff-oatao@ listes-diff.inp-toulouse.fr 


\title{
Anticipating aging failure using feedback data and expert judgment
}

\author{
François Peres ${ }^{\mathrm{a}, *}$, Leilla Bouzaïene ${ }^{\mathrm{a}}$, Jean-Claude Bocquet ${ }^{\mathrm{a}}$, François Billy ${ }^{\mathrm{b}}$, \\ André Lannoy ${ }^{\mathrm{b}}$, Philippe Haik ${ }^{\mathrm{b}}$ \\ ${ }^{a}$ Ecole Centrale Paris, Laboratoire Génie Industriel, Grande voie des Vignes, 92295 Châtenay-Malabry, France \\ ${ }^{\mathrm{b}}$ EDF-R\&D, 6 Quai Watier, 78401 Chatou Cedex, France
}

Received 19 April 2005; received in revised form 10 September 2005; accepted 30 November 2005

Available online 18 April 2006

\begin{abstract}
This paper presents a methodology for anticipating failures in a component up to the end of its life cycle. Often, feedback data is not sufficient and must be complemented by the analysis of expert judgment. The methodology developed aims at anticipating the degradation mechanisms responsible for aging, and evaluating their relevance and related uncertainties. This is necessary information for risk analysis related to the operating of a component up to the end of its life cycle. Lastly, the methodology is applied to a nuclear component.
\end{abstract}

Keywords: Maintenance; Aging; Anticipation; Potential failures; Life cycle management; Expert judgment

\section{Introduction}

In the framework of good management of the life cycle of an industrial installation and a possible extension of its service life, it is necessary to be able to predict the effects of aging. To do this, one must analyze potential failures that may occur and propose solutions for avoiding them or reducing the seriousness of their effects [1]. This paper proposes to examine this industrial problem. Anticipation is by its nature based on feedback. However, the data available is not always complete or sufficient to carry out the needed analysis. To complement and enrich the data, we recommend exploiting the information available on "analogous" equipment, "third party" feedback from other companies and expert judgment. Our objective is therefore to develop a methodology by which it is possible to anticipate potential failures due to aging using both feedback and expert judgment.

\footnotetext{
*Corresponding author.

E-mail addresses: francois.peres@enit.fr (F. Peres),

leila.bouzaiene@1gi.ecp.fr (L. Bouzaïene), jean-claude.bocquet@1gi.ecp.fr (J.-C. Bocquet), francois.billy@edf.fr (F. Billy), andre.lannoy@laposte.net (A. Lannoy), philippe.haik@edf.fr (P. Haïk).
}

The anticipation methodology that we have developed brings into play three distinct overlapping processes, outlined in the diagram below (Cf. Fig. 1).

The different phases of the methodology represent a procedure, which can be qualified as a Global Anticipation Process (GAP). The third phase of this process (seen in the first column of Fig. 1) can itself be subdivided into a series of 5 steps, which we call the Surveying process. Finally, the entire Surveying process is assisted by a parallel process called the Expert Elicitation Process. In order to improve the understanding of the structure we will label the steps in the GAP as "phases' keeping the words "step" for the surveying process and "stage" for the expert elicitation process.

After having introduced the context of the studies and the players involved in the production and exploitation of the results, we will describe the three processes and will apply the methodology in an industrial context.

\section{Context and background}

In any predictive approach, it is essential to be able to identify the basic data, which can provide useful and complete information needed for decision-making. We call this information "anticipation data". It is also important 
to define clearly the objectives of the method and the end results one wishes to obtain. As these results are destined for decision-makers, we call them "decision-support data".

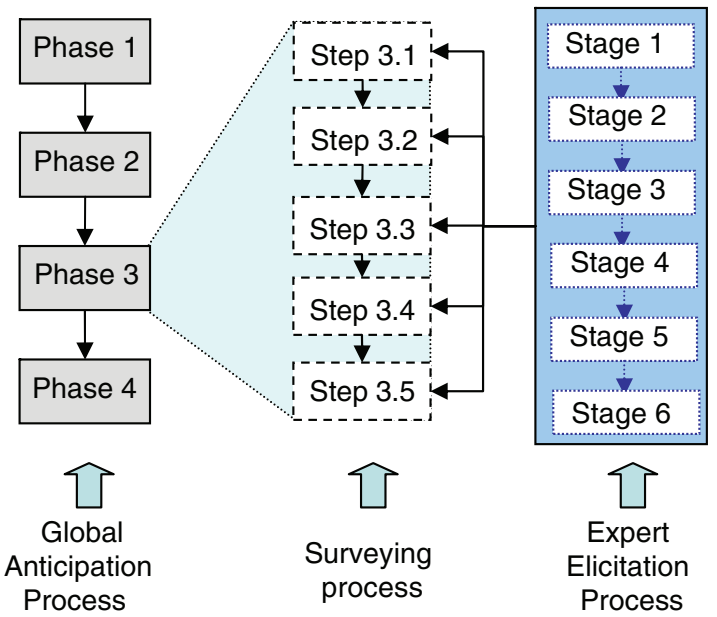

Fig. 1. Structure of the work.

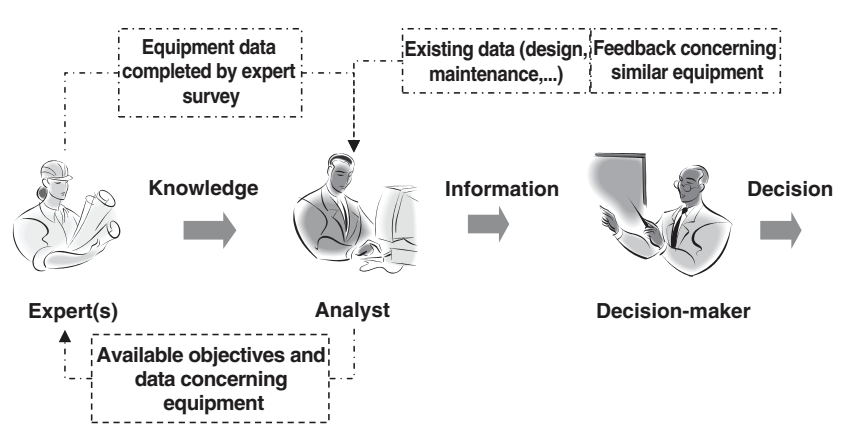

Fig. 2. Context of use of expert knowledge.
Furthermore, it is equally essential to be able to localize the different types of information and identify information flows among the various players and knowledge sources.

We have identified three types of players in the "anticipation" process: analyst, expert and decision-maker.

It is the analyst who coordinates the anticipation process. His role is to gather the information needed for anticipation, and to synthesize it to provide data for decision-making. To enrich this data concerning the/ or the state of the equipment, the analyst may also gather feedback data on equipment analogous to that being investigated as well as the experts opinion (Fig. 2).

It is the expert who has the knowledge and the expertise to anticipate failures or degradation mechanisms. To do so, he will need a certain amount of data and influencing variables on the basis of which he can make an assessment.

The decision-maker is the one who, on the basis of the synthesized data provided by the analyst, chooses the "best" solutions and compromises in accordance with decision-making processes, while remaining faithful to corporate strategic guidelines. The optimum solution will often be a compromise.

In order to facilitate comprehension of the text we give the definitions of a number of key words in Table 1 below.

\section{Global anticipation process}

We start with the description of the essential features of the global anticipation process (Cf. Fig. 3), the different phases it implies and the various methods and tools required.

Phase 1. Definition of the context and objectives of the anticipation process: This phase is dedicated to the description of the context and the aim of the study as well

Table 1

Definitions of main scientific terms used within the framework of this study

\begin{tabular}{ll}
\hline Word & Définition \\
\hline Anticipation & $\begin{array}{l}\text { Identification of events which might be detrimental in terms of safety, availability or cost, before they occur, so as to } \\
\text { evaluate the risks they represent and to prepare and implement the appropriate measures of preventive or unscheduled } \\
\text { maintenance. }\end{array}$
\end{tabular}

Degradation mechanism Physio-chemical change in the characteristics of a material under specific conditions of temperature or pressure or in a specific chemical environment. This progressive alteration over time may cause degradation of the material with measurable effects (a crack, for example). With time, this degradation may further deteriorate and, beyond a certain threshold, may cause a partial alteration or total loss of function in the component; this is a failure. It can be identified by a failure mode (e.g. a leak).

Failure

Loss of capacity on the part of a set of components to perform the required function(s) at the level of performance defined in the technical specifications.

Aging

Process in which the characteristics of a component change with time or with use.

Unscheduled maintenance

Passive equipment
Set of tasks, performed on a structure, which are generally preventive and non-repetitive; they may be generic; they are economically costly.

Part of the structure that does not involve dynamic component. Such equipment does not normally undergo preventive maintenance checks.

Sub system of the installation that directly participates in the production of the expected service or product. This type of equipment is subject to preventive maintenance. 


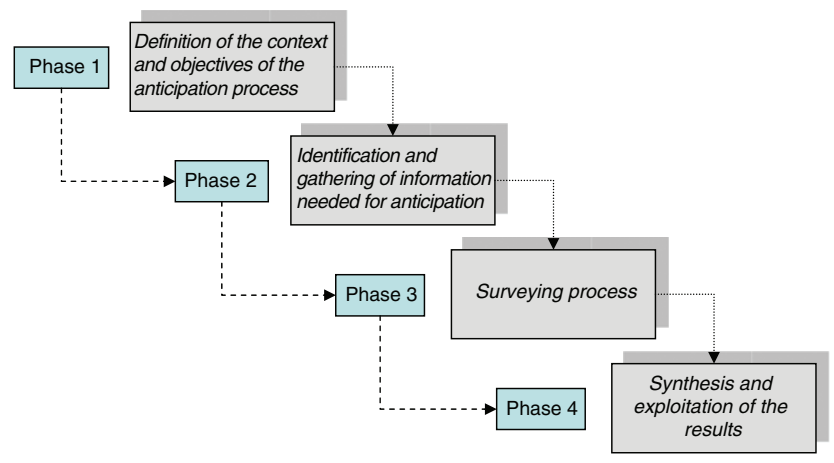

Fig. 3. Description of the global anticipation process.

as the results that are hoped for. To this end, a document is provided to the experts in order to specify the environment and objectives of the survey, the important definitions and the different steps of the methodology.

Phase 2. Identification and gathering of information needed for anticipation: This phase will enable the analyst, generally not an expert on the component, to determine the information that will help him communicate with the equipment experts, and to ask the right questions. For the next phase, this information will provide input data, which will help stimulate expert responses. During this phase, one type of information is particularly needed: failure history of equipment different from the one studied but made of the same materials, with similar design and manufacturing procedures, found in the same operating or maintenance environment or fulfilling the same functions. We call such equipment "analogous" equipment.

Phase 3. Surveying process: This phase will be described later on as a specific subprocess. Let us just point out that at each step, one must set objectives for the survey, identify the experts to be questioned and choose the questioning procedure: individual or collective questioning. A certain number of tools and methods have been chosen or implemented to guide or facilitate the work at this level, depending on the end objective. Let us mention for instance the use of Bayesian networks to evaluate the relevance of the mechanisms, or the choice of the TRIZ method to identify potential preventive solutions.

Phase 4. Synthesis and exploitation of the results: This phase is dedicated to the treatment of the results of the anticipation process, but also the analysis of the different phases that led to these results. To exploit this information, an easy-to-use format is required which allows one to simply to retrieve the data needed so as to facilitate their reuse and updating. For a given piece of equipment, each component/degradation mechanism pair has to be analyzed in order to capitalize the information concerning the material affected by the mechanism, the operating conditions that promoted the appearance of the mechanism, the measurable effects, the failure modes, the existing feedback and the monitoring and preventive maintenance procedures. This data will be useful in future studies, to retrieve feedback on "analogous" equipment. Furthermore, at the end of the study, one must provide the results to the decision-makers and participating experts. This can be done in a document that sums up the results of the anticipation process.

\section{Surveying process}

This paragraph is dedicated to the description of the third phase of the global anticipation process, which represents the heart of the methodology since it leads to the identification and the evaluation of the degradation mechanisms. A descending approach appeared to be the best suited for describing this process. Consequently, the process to be followed to anticipate an event can be:

- identify potentially detrimental events,

- evaluate their consequences and seriousness,

- prepare and implement the appropriate maintenance measures.

Because our work deals with life cycle management, we shall concentrate on anticipating failures due to aging. Any equipment, which ages is subject to mechanisms of degradation which act on its component in specific ways. To anticipate failure due to aging, the degradation mechanism which may initiate it (trigger) has to be identified. Its relevance must also be evaluated, considering the evolution over time of the measurable effects it may have (kinetics). Next, the corresponding failure modes and their consequences are determined. It is then possible to identify the maintenance measures needed to avoid or slow the mechanism. In the context of life cycle management, the efficiency of these maintenance measures from the perspective of safety and costs has to be considered.

The process of anticipation would seem to be more suited to passive components. Generally, such equipment is subject to only one degradation mechanism. The kinetics of degradation are slow and progressive. If the equipment cannot be replaced, its lifetime may condition that of the installation as a whole. Replacement of such components can only be exceptional and occasional. However, active components important for safety or critical in terms of maintenance costs or availability may also deserve anticipatory measures. Unlike passive components, active components are those subject to significant wear, often quite rapid, due to several compounded degradation mechanisms; they are subject to regularly scheduled preventive maintenance operations, and in some cases, replacement. For active components, the degradation mechanisms which trigger the failure cannot be isolated; one must therefore identify and anticipate the degradation or failure modes understanding that a mode may be attributable to several mechanisms. Within this framework, 

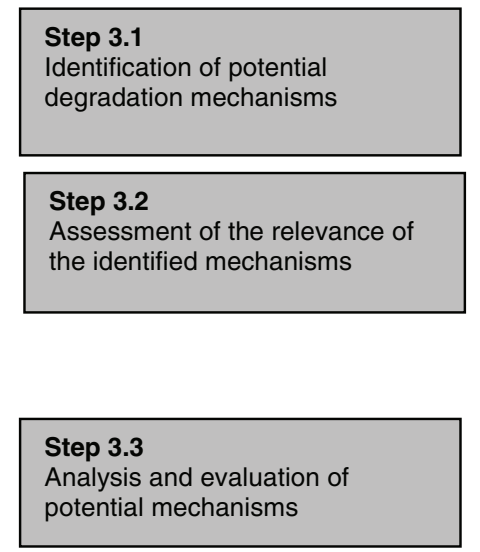

\begin{tabular}{|l|}
\hline Step 3.4 \\
Identification of potential \\
preventive solutions
\end{tabular}

\section{Step 3.5}

Evaluation of suitability of preventive solutions

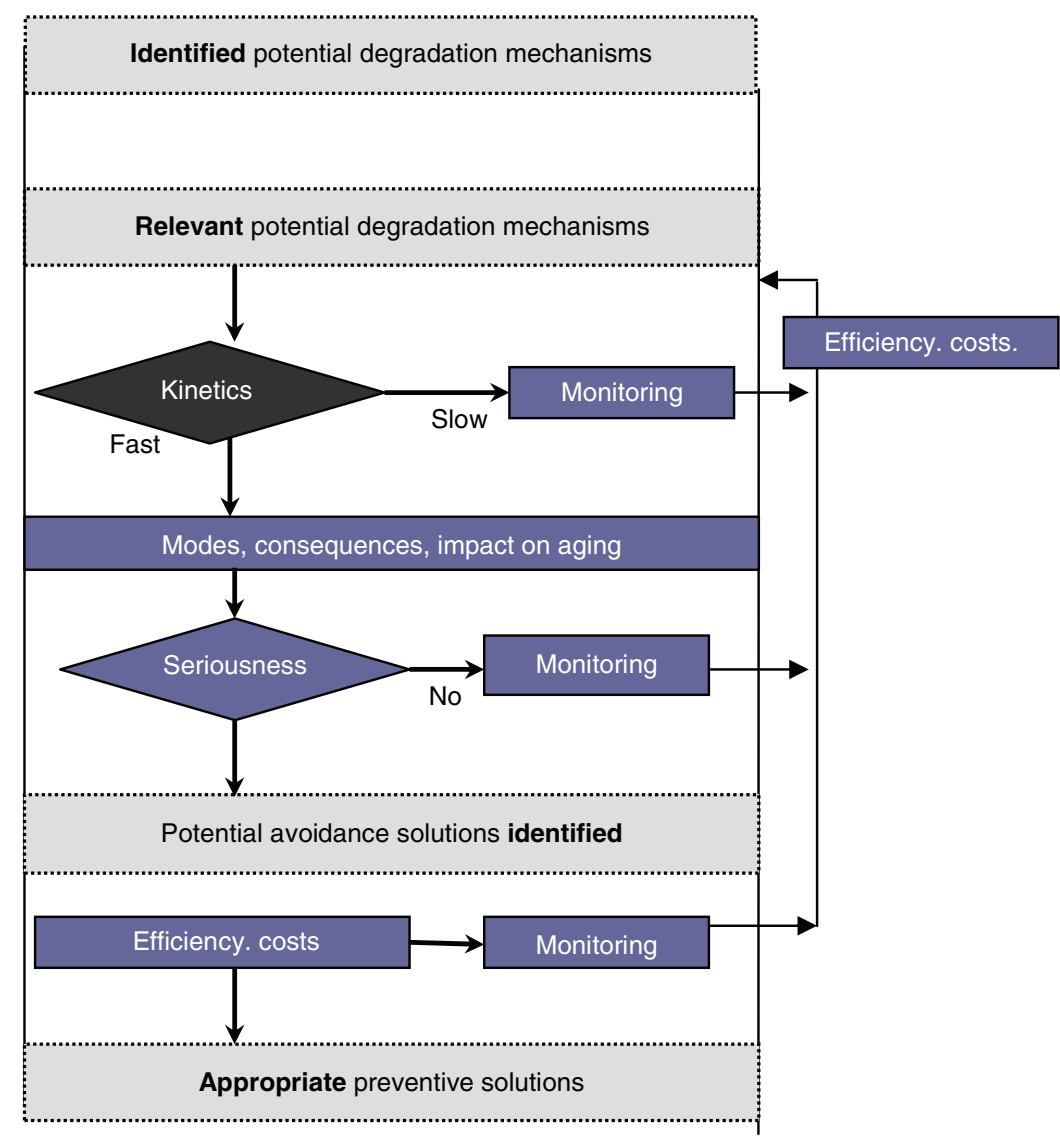

Fig. 4. Description of the surveying process. the process of anticipating potential failures due to aging (Fig. 4) involves the following steps ${ }^{1}$ :

3.1 Identification of the potential degradation mechanisms (for a passive component) and the potential failure modes (for an active component).

3.2 Assessment of the relevance of these mechanisms.

3.3 Analysis and ranking of the relevant mechanisms (or modes): potential failures (kinetics, seriousness, measurable effects, consequences).

3.4 Identification of potential avoidance solutions.

3.5 Assessment of the suitability of these solutions in terms of efficiency and cost.

\section{Expert elicitation process}

\subsection{Tools and methods}

Functional analysis, design documents and, most particularly, Reliability Centered Maintenance (RCM) studies can inform about the potential failures of a piece of equipment. Feedback can provide information on failures actually

\footnotetext{
${ }^{1}$ The digit 3 , which appears at the beginning of each step is to remind that this process belongs to the third step of the global anticipation process described earlier in Section 3.
}

observed in equipment. However, if the environmental, operating or maintenance conditions or the duration of operation of the equipment change in relation to those considered at the time of design, only expert judgment is capable of predicting the impact of the changes. Drawing on existing data, the expert can identify the potential failures, which might occur subsequent to these changes. He is therefore an important player in the anticipation process.

As it can be seen on Fig. 4, each step of the surveying process can be provided with information resulting from a process of expert questioning. Such a process is called elicitation.

Ballay [2] defines the expert as being the "person who has the knowledge". In [3], Lannoy and Procaccia list four situations, which require recourse to expert judgment in the field of dependability:

- completing, validating, interpreting and integrating existing data; assessing the impact of a change (in design, manufacturing, operation, maintenance or environment),

- predicting the occurrence of future events and the consequences of a decision,

- determining the present state of knowledge in the field,

- providing the elements needed for decision-making in the presence of several options. 
Table 2

Methods for expert elicitation in the context of nuclear safety

\begin{tabular}{lll}
\hline NUREG-1150 [5], & STUK-VTT [6], & NNC \\
FEJ-GRS & KEEJAM [7] & CTN-UPM \\
TUD [8] & & \\
\hline
\end{tabular}

"Anticipation" relates to three of these situations. First, the problem is to complete and validate feedback data, which will enable the identification of a certain number of observed failures. Next, one must evaluate the impact of any changes in relation to the initial design (for example, an extension of the service life beyond the period planned at the time of design) and estimate the probability of occurrence of future events, which the expert must identify and evaluate in terms of their seriousness. Lastly, the expert must provide decision-makers with the elements needed to make their decisions and choose the alternative, which will enable the avoidance or delay of potential failures identified.

As expert judgment has often been used in dependability applications, the choice of an ascending method was chosen to handle this aspect of the methodology to be developed. A certain number of methods for soliciting expert knowledge were examined to identify or build up a method adapted to the needs of anticipation [1].

Seven of these methods have been used essentially in nuclear safety applications [4] (Table 2):

In addition, we looked at the methods for questioning experts used in these different approaches:

- LCM (Life Cycle Management) [9],

- TRIZ-AFD (for Anticipatory Failure Determination, as well as for identifying solutions and design-support) $[10,11]$,

- RIPBR (Risk-Informed, Performance-Based Regulation in nuclear safety and maintenance support) [12],

- PMDA-PIRT (Proactive Materials Degradation Assessment-Phenomena Identification and Ranking Table, for anticipating degradation of materials due to aging) [13].

A description of these methods can be found in [1], except for PMDA-PIRT, identified in January 2004. PMDA-PIRT is a method in the course of development since 2003 by the US-Nuclear Regulatory Commission (NRC). It is a method for anticipating degradation mechanisms related to equipment aging in nuclear plants. The objectives of the method are to:

- identify and rank the degradation mechanisms likely to affect critical plant equipment,

- evaluate the efficiency of periodic inspections or implement new procedures for corrective maintenance or replacement,

- enable improved understanding of observed, but also potential degradation mechanisms.

\subsection{Classification of methods for surveying experts}

In order to compare the 11 methods studied, we proposed to classify them in terms of their suitability for the purposes of anticipation and the efforts required, using an anticipation/effort diagram. The objective was to identify the methods most useful for anticipation and which do not require major efforts for implementation (see Fig. 5).

The $X$-axis, representing the effort needed for implementation, expresses the ease of application of the method. This effort takes into account the number of experts to be surveyed, the number of times they are to be questioned, the time needed for the process and the degree of complexity of the different phases of questioning and of the tools used. The $Y$-axis, more specific to anticipation, enables the evaluation of the suitability of the method to this context. This aspect takes into account the objectives of the method, the different applications made, the multidisciplinary nature of expert teams and the suitability of the tools from the perspective of anticipation.

Six experts from different disciplines contributed to the classification of the methods. In the paper the experts are considered as having the knowledge. The experts were chosen for the survey because they had already applied one or several methods we wanted to compare.

This classification points out the existence of three families of methods:

Family $A$ falls in quadrants 1 and 4 of the diagram and is composed of the CTN-UPM, NNC, TUD and FEJ-GRS methods. These methods are of no real interest for anticipation.

Family $B$ falls in quadrant 2 of the diagram and is composed of the TRIZ-AFD and LCM methods. These two methods seem well suited to anticipation and do not require much effort for implementation. However, each corresponds only partially to the needs of anticipation:

- TRIZ-AFD enables the identification of failures and maintenance solutions but gives no means of evaluating them.

- LCM enables the identification and evaluation of maintenance solutions in relation to known failures. It recommends systematic monitoring of critical equipment and proposes solutions in the event of an observed failure. This reactive method does not, however, enable the anticipation of failures, which have never occurred. This type of approach, which presents safety risks and, in some cases can generate significant expenditure, is inadequate in any field where safety is a factor of prime importance.

Family $C$ falls in quadrant 3 of the diagram and is composed of the PMDA-PIRT, RIPBR, STUCK-VTT, NUREG-1150, KEEJAM methods. All of these methods have benefits for anticipation but require major efforts for implementation. It was therefore necessary, for each 


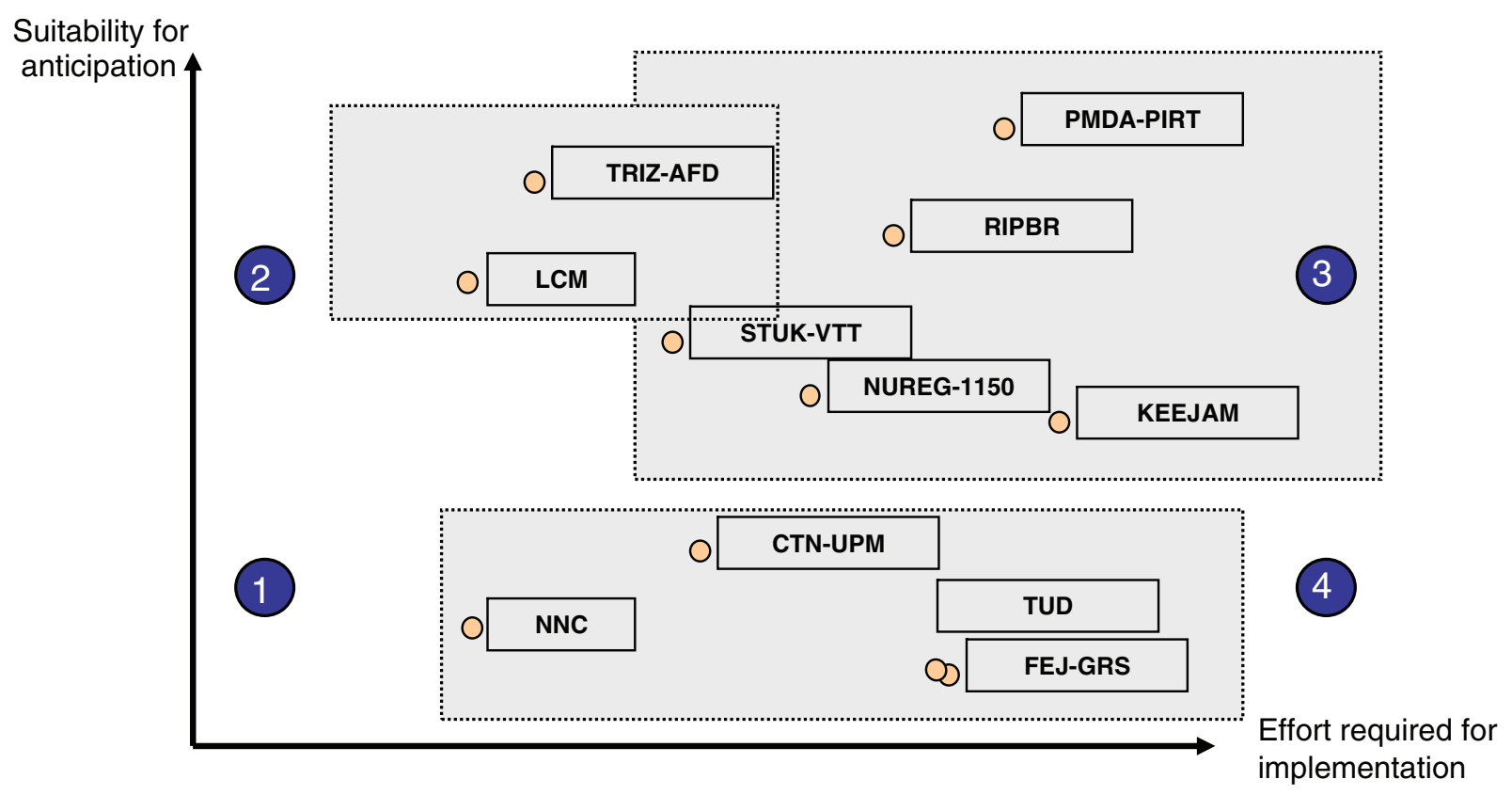

Fig. 5. Classification of methods for surveying experts.

method, to identify (1) the positive points, which could be integrated in a global anticipation method and (2) the weak points that must be avoided.

\subsection{Assessment of the methods in relation to anticipation}

The different methods likely to deal with anticipation are presented in Table 3. The benefits from the perspective of anticipation as well as the weaknesses of each method are also discussed.

\subsection{Lessons learned from the analysis}

This overview showed that none of the methods studied really provides a global solution to the objective of anticipation. However, it did point out certain characteristics beneficial for building up a method for surveying experts with a view to anticipation:

1 Drawing on methods to stimulate creativity (a concept found in TRIZ-AFD).

2 Surveying in two phases: one collective and one individual (NUREG-1150).

3 Breaking down the problem into several steps and questioning experts from various disciplines (FEJGRC).

4 Formalizing exchange among the experts and exploiting existing knowledge (KEEJAM, STUK-VTT).

5 Simplification of the "probability" aspect for the experts and structuring of results (STUK-VTT).

Moreover, this bibliographical review of existing methods revealed the generic stages in the process of surveying experts. They are introduced in Fig. 6.

\section{Application to a passive component in a nuclear plant: the pressurizer}

To validate the proposed approach, it is now being practically applied to a passive component: the pressurizer, a component, which regulates the pressure in the primary cooling system of a nuclear power plant. The test will enable the evaluation of the feasibility of the method and identifying any difficulties encountered in actual practice (Fig. 7).

Step 1. Definition of the context and objectives of the anticipation process: Was carried out using a document that summarized the industrial context of anticipation, as well as the objectives. Various definitions and the methodology phases were presented. This document was sent to the selected experts who then accepted to participate in the practical application.

Step 2. Identification and gathering of information needed for anticipation: A manual for finding pertinent data was produced. It will make this phase easier in future practical applications. The result of this phase was presented in a document containing all the information required for anticipating the condition of the pressurizer. The following information was presented:

Functional data: Functional data includes the global equipment functions and the function-equipment breakdown, which breaks equipment down into groups of components performing the same function.

Design data: This data includes all elements relative to the design of the component. It groups the equipment components, the technical diagrams, the geometric dimensions of the different components, the materials used, the manufacturing procedures and the related costs.

Data on materials: This data is related to the different materials used to make up the component. It groups the 
Table 3

Assessment of the method in relation to anticipation

\begin{tabular}{lll}
\hline Method & Benefits from the perspective of anticipation & Drawbacks \\
\hline NUREG -1150 & $\begin{array}{l}\text { Experts surveyed in two phases, one collective and one } \\
\text { individual; corresponds quite well to the objective of } \\
\text { anticipation (creativity and analysis) }\end{array}$ & $\begin{array}{l}\text { Training the experts with regard to probability concepts is } \\
\text { a constraint. }\end{array}$
\end{tabular}

\section{STUK-VTT}

NNC

FEJ-GRC

KEEJAM

CTN-UPM

TUD

LCM

TRIZ-AFD

RIPBR

PMDA-PIRT
The use of bayesian networks to facilitate questioning of experts unfamiliar with probability concepts is an interesting idea.

The use of groups of experts from different disciplines corresponds well to the objective of anticipation.

The breakdown of objectives and the use of groups of experts from different disciplines correspond well to the objective of anticipation.

This approach based on knowledge engineering is constructive for anticipation from the perspective of exploitation of knowledge.

The method enables obtaining quantitative estimations; it appears better suited to an analysis process.

The method enables obtaining quantitative estimations; it is also more appropriate for an analysis process.

The objectives are similar (managing aging) but the anticipation aspect is insufficiently developed. A very simple, inexpensive method.

This method of anticipation is above all well suited for choosing solutions for dealing with a failure. It does not enable answering questions related to the relevance and seriousness of potential failures.

This method of maintenance optimization is actually quite close to our objectives. It clearly expresses the need for integrating anticipation based on expert judgment.

This method corresponds perfectly to the objective of anticipation, though it goes no further than identification and ranking of potential degradation mechanisms. The results constitute input data for managing maintenance and the life cycle of critical equipment in nuclear plants.
The method is more suited to quantitative estimation of parameters (e.g. physical parameters).

The method is not very formalized.

The method is complex and difficult to implement, as it involves several groups of experts.

The method is complex and costly to implement (long 15step process).

The method is experimental, and only now being developed.

The method is complex and costly to implement.

A systematic method, which leaves little room for creativity and does not enable the identification of new failures.

The method is experimental, and still being developed.

The method is still being developed.

The method is difficult to implement since it requires several experts over a long period of time. It is still theoretical, not yet having been validated by any practical application.

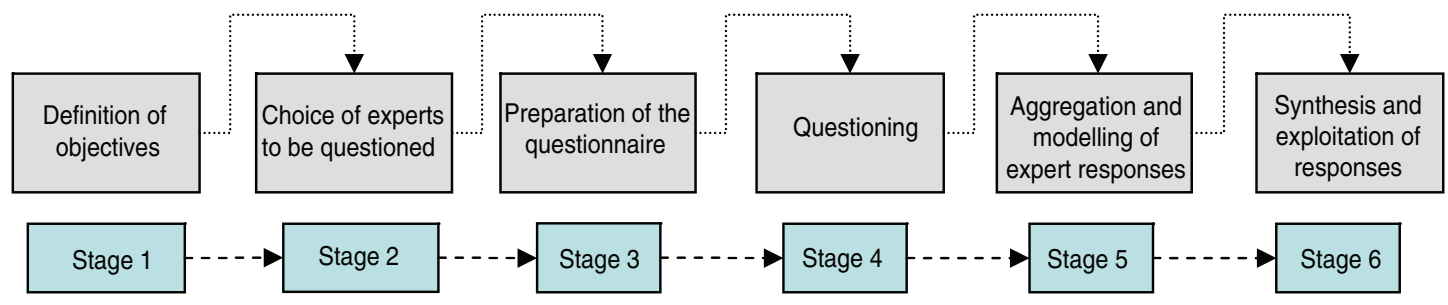

Fig. 6. Description of the expert elicitation process.

chemical and mechanical characteristics of the materials, their properties and a description of any welds (if appropriate).

Operating parameters: Operating parameters include the temperatures, pressures, flow rates and chemical environments of the component in question.

External environment data: It gives information about the ambient environment in which the equipment operates, and its interactions with other components.
Operating data: This data is related to the different operating modes for the equipment, the number of cycles and the number of hours of operation.

Maintenance data: Maintenance data is in relation to preventive maintenance programs, but also includes the various costs of maintenance, data on obsolescence, regulations and reports on safety, reliability and aging. 


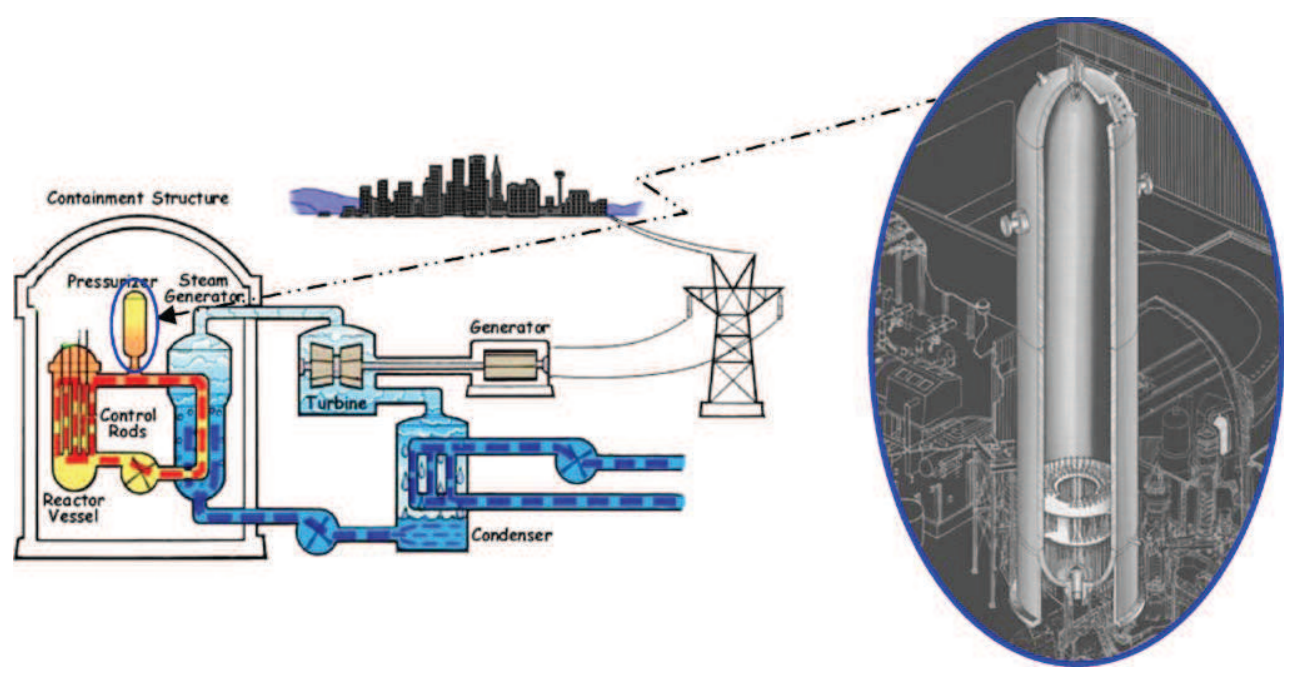

Fig. 7. Pressurizer of a nuclear plant.

Feedback data: It includes traditional feedback from the company, feedback on "analogous" equipment and from plants outside France, and reports on reviews of the state of the art.

In our application, it became clear that the information most useful for drawing up a list of the potential mechanisms and modes were technical diagrams, operating and environmental data and feedback data.

Step 3. Surveying process: The process is now under way. The first step (identifying potential degradation mechanisms) is completed. The second step (study of the relevance of the mechanisms identified) is being performed. The following paragraphs describe these two steps.

Step 3.1. Stimulation of expert knowledge to identify potential degradation mechanisms: This anticipatory step is very important, as one must identify the degradation mechanisms, which could be the source of potential failures. The analyst knows the degradation mechanisms identified in Reliability Centred Maintenance studies on the equipment in question (where these exist) and those observed in the component and reported in feedback. To identify new mechanisms, he may make use of a list of all degradation mechanisms. To build up this list, he will consult several studies on degradation mechanisms. In our study, the most exhaustive list possible was drawn up.

Feedback on analogous equipment is another helpful source. A component made of the same materials may have had observed failures due to degradation mechanisms which had not been identified for the component being studied. In this case, one must see whether or not the conditions under which they appeared suggest that one might anticipate failures in the equipment being studied.

In this step, the analyst will ask the experts to try to imagine what the component's potential degradation mechanisms might be. Knowing that exchange among the experts can stimulate the emergence of ideas, collective questioning would appear to be best suited to this step. A structured method has been fine tuned to enable stimulat- ing creative thinking on the part of the experts and helping them to make optimum use of the information gathered and their own knowledge [14]. To prepare this method, a bibliographical review of methods to stimulate creativity and group thinking was carried out.

\section{- Preparation of the group meeting}

Starting with a global list of degradation mechanisms and failure modes, the method developed provides for several successive filters (see Fig. 8). These filters oblige the experts to go over the global list and eliminate irrelevant mechanisms in accordance with a predetermined logic. To complete the global list and ensure that the final list is exhaustive, the experts are asked to do a preliminary exercise: each must note down the potential degradation mechanisms and failure modes for the pressurizer. The new mechanisms are integrated in the global list before the group survey.

Six experts with varying professional backgrounds accepted to participate in this first survey step: a pressurizer expert, a reliability and feedback expert, an expert in equipment materials, an expert in degradation mechanisms, a chemical expert and an expert in mechanics and plant operation. The two documents produced in phases 1 and 2 were sent to the experts. Two facilitators presented the information and questioned the experts; two scribes reported on the process and provided the results of the questioning.

- Results and evaluation of the method The group meeting enabled the identification of 18 potential "degradation mechanism/zone" pairs and 16 potential "aging effects/zone" pairs for the pressurizer over a given period of operation. Six degradation mechanisms (e.g. stratification due to thermal fatigue) and two aging effects (e.g. thermal cracking) were added to the initial list by the experts. The "multidisciplinary" aspect was much appreciated by the experts, and judged to be important and necessary. The method was judged 


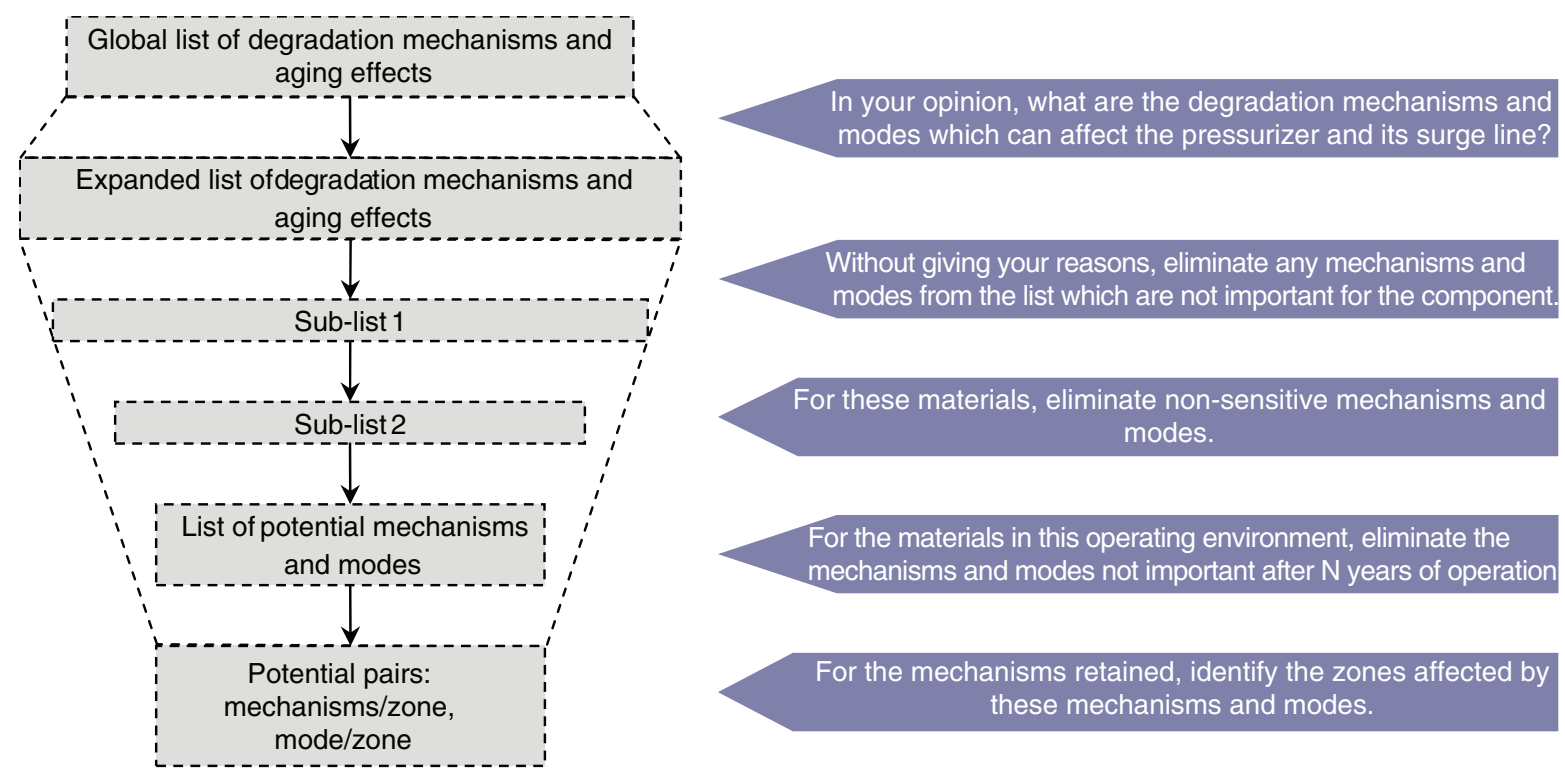

Fig. 8. Survey of experts to identify potential degradation mechanisms.

efficient with regard to long-term and accidental degradations. The method was judged exhaustive thanks to the use of the global list, which prevented omissions.

The experts are motivated to pursue the experiment.

Step 3.2. Study of the relevance of the degradation mechanisms: example of the Bayesian network: Among the degradation mechanisms identified in the first assessment step, a certain number may be found to be irrelevant. To verify their relevance, we must consider all the parameters, which may lead to their appearance. The tool needed to facilitate the expert's job must identify any cause-effect relationship among several parameters, which might promote the appearance of the degradation mechanism in question.

A causal diagram fills this need perfectly but the expert cannot always say with certainty that the degradation mechanism is relevant; he can only give an approximate opinion, since he is projecting into the future. To quantify these approximations, there is a tool, which links probability values to a causal diagram: the Bayesian network.

This graphic representation of the cause-effect relationships among the different parameters and the relevance of the degradation mechanisms allows the expert to visualize links, which were only tacit in his mind. However, he is not always able to associate probabilities with these different links, but may give more or less favorable opinions. It is then the role of the analyst to pose the appropriate questions, which will later enable the establishment of probabilities.

Fig. 9 shows one example of a network enabling the evaluation of the relevance of thermal fatigue. Other networks were constructed, to study the relevance of the corrosion mechanism, for example, or evaluate the efficiency of an existing or new avoidance solution.
The first step is to build the network structure. To do this, we must identify the parameters with a bearing on the relevance of thermal fatigue. One expert helped to build the network and another validated the structure. This network may be considered to be generic and may now be applied to any component subject to thermal fatigue.

The output node is the relevance of thermal fatigue after $N$-years, with the possibilities: yes/no. It gives the probability that the fatigue mechanism is relevant or not. The network is composed of 7 input variables in 2 or 3 modes and of 4 intermediate variables in 2 or 3 modes (see Fig. 9). The a priori probabilities are given by feedback or expert judgment. The conditional probabilities were most often given by expert judgment. As the expert is not always able to associate probabilities with the different variables, a questionnaire was drawn up for the experts. The analyst can then express the experts' qualitative responses in terms of probabilities.

Example of one question: Do you think that the number of transients after $N$-years will be "low" or "high"? The possible answers for each mode are 1: impossible, 2: possible, 3: probable, 4: very probable, 5: certain. The analyst then associates probabilities to this scale.

\section{Conclusion}

In the framework of this study, a method was developed to anticipate potential failures due to aging. It consists in four phases: definition of the context and objectives, identification and gathering of the information needed for anticipation, surveying of experts, and synthesizing and exploiting results.

When questioning the experts to obtain input for anticipation, five steps are proposed to identify potential degradation mechanisms (for passive components) or potential failure modes (for active components), (1) study 


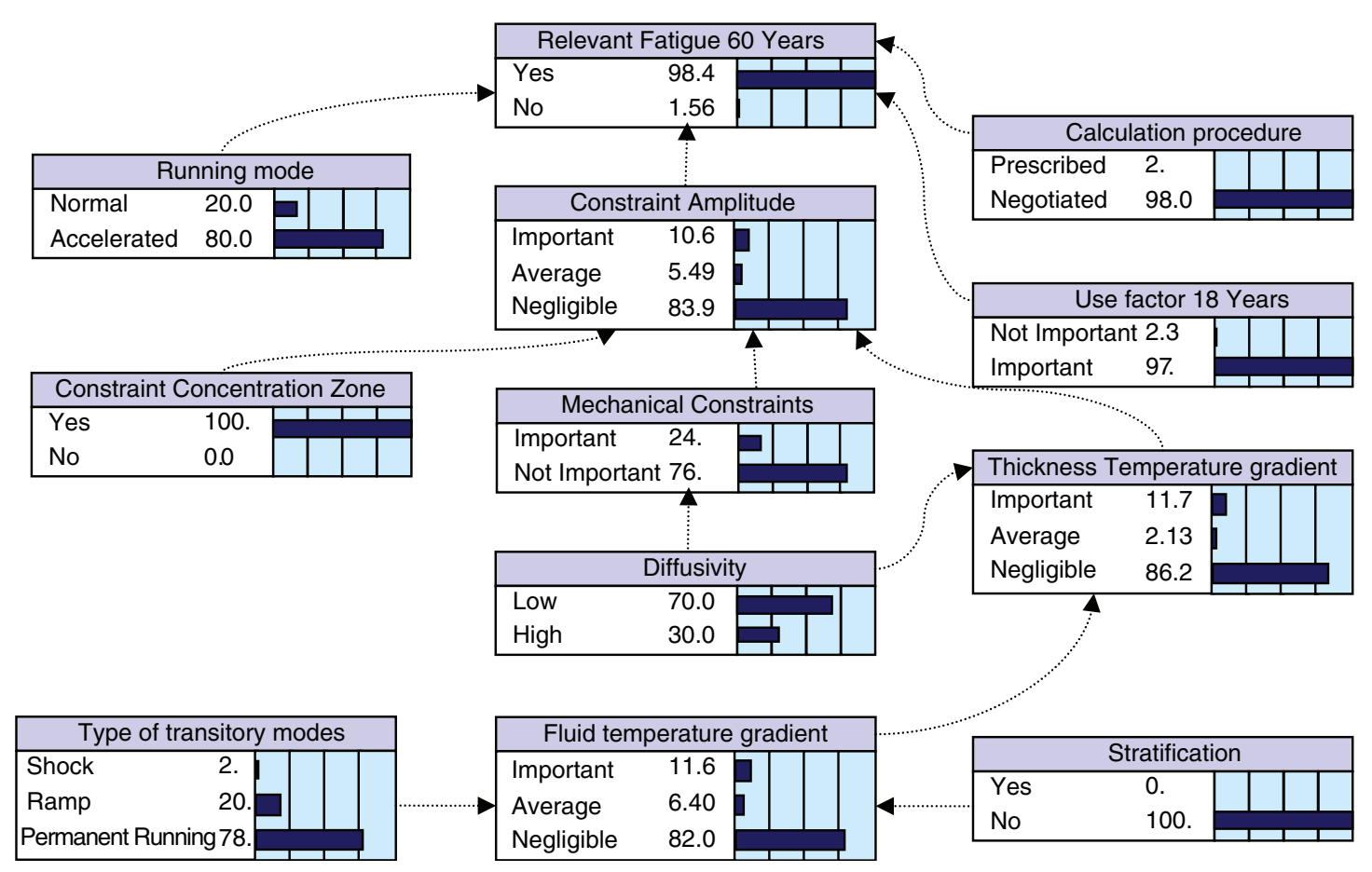

Fig. 9. Example of a Bayesian network to study the relevance of thermal fatigue in the pressurizer after $N$-years.

the relevance of these mechanisms (or modes), (2) analyze and rank the relevant mechanisms (or modes) (3) analyze and rank potential failures (kinetics, seriousness, effects of aging, consequences) (4) identify potential avoidance solutions and (5), examine the relevance of these solutions in terms of efficiency and cost.

Having reviewed the state of the art in methods for questioning experts, we identified a generic process. At each step described above, we then referred to this generic process which consists in defining the objectives behind the questions, choosing the experts to be surveyed, preparing the questionnaire (selecting appropriate questions), surveying the experts, aggregating and modeling the experts' responses and finally synthesizing and exploiting the question results.

One application of the methodology developed is now under way. It relates to a passive component in a nuclear power plant: the pressurizer. This application will enable the evaluation of the feasibility of the method and the identification of any practical difficulties encountered. This article presents the initial results of this application: implementation of a method for stimulating creative responses in the framework of a meeting of experts from different disciplines to identify potential degradation mechanisms; and the use of Bayesian networks to assess the relevance of the mechanisms identified.

This approach was developed for a specific industrial context, which is the nuclear industry. It could be applied to other sectors which make use of installations and components with long lifetimes or which use specific technologies and are subject to high safety constraints. Generally, there is little feedback (and it is therefore all the more valuable) and the benefits of anticipation are therefore great. We might point to the example of the aerospace or chemical industries. In these particular sectors, certain specific equipment can be very expensive, and replacement poses significant technical problems and can paralyze operations.

The approach developed here enables the identification of potential problems, which may be caused by aging, and adapting maintenance so as to limit the consequences. It should therefore be an essential first step in any predictive technico-economic study, as it enables the assessment of the physical condition of components.

Finally, only failures due to physical aging were considered in this study. The framework could be broadened to take into account other causes of failure such as human error or diagnosis-support, for example, or to conduct risk analyses or predictive studies.

\section{References}

[1] Bouzaïene L, Billy F, Bocquet J-C, Haïk P, Lannoy A, Peres F. Expert judgment methodology for failure anticipation in nuclear power plants. In: Bedford and Van Gelder (editors), Safety and reliability. Lisse: Swets \& Zeitlinger; 2003. p. 195-200.

[2] Ballay J-F, Capitaliser and transmettre les savoir-faire de l'entreprise, Eyrolles, 1997.

[3] Lannoy A, Procaccia H. L'utilisation du jugement d'experts en sûreté de fonctionnement, Editions Tec \& Doc, Décembre, 2001.

[4] Cojazzi G, Fogli D. Benchmark Exercise on Expert Judgment Techniques in PSA Level 2, Extended final report, 2000.

[5] Keeney RL, et al. Use of expert judgement in NUREG-1150, Nuclear engineering and design, vol. 126. Amsterdam: North-Holland; 1991. p. 313-31. 
[6] Pulkkinen U, Holmberg J. A method for using expert judgement in PSA. STUK-YTO-TR 129, 1997.

[7] Cojazzi G, et al. KEEJAM: A knowledge engineering methodology for expert judgment acquisition and modelling in probabilistic safety assessment, actes du ESREL'97. International conference on safety and reliability, 17-20 Juin, Portugal, 1997.

[8] Cooke RM, Goossens LJH. Procedure guide for the use of expert judgement in uncertainty analyses, actes du ESREL'96-PSAM III. International conference on probabilistic safety assessment and management, 24-28 Juin, Grèce, 1996.

[9] Melvin A, et al. Demonstration of life cycle management planning for systems and components with Pilot applications at Oconee and Prairie Island Nuclear Stations, Rapport interne EPRI, 2001.

[10] Guarnieri F, Haïk P. AFD. Une nouvelle méthode pour l'identification and la maîtrise des défaillances: présentation, illustration and perspective. Proceedings of the conferences of ESREL 2002, Lambda $\mathrm{Mu}$ 13, 2002.
[11] Kaplan S, Visnepolschi S, Zlotin B, Zusman A. New tools for failure and risk analysis: anticipatory failure determination (AFD) and the theory of scenario structuring. Ideation International Inc; 1999.

[12] Golay MW. Improved nuclear power plant operations and safety through performance-based safety regulation. J Hazardous Mater. 2000;71:219-37.

[13] 138.(67) Draft report on the proactive materials degradation assessment (PMDA). Phenomena identification and ranking table (PIRT) for pressurized water reactor plant types (Refer to SRM M041108AB). ML051640246 2005-07-05 6 + KBR1SISP20050810 M041108AB SRM-M041108AB 2005-07-05 2005-08-10 ML0517$40450+$ July 5, 2005 MEMORANDUM TO: Chairman Diaz Commissioner Merrifield Commissioner Jaczko Commissioner Lyons FROM: Luis A. Reyes /RA Martin J. Virgilio for/Executive Director for Ope

[14] Bouzaïene L, Haïk P, Peres F. Stimulation croisée d'expertise de maintenance: application au parc nucléaire français, Actes des conférences ESREL 2002, Lambda Mu 13, 2002. 